\title{
Las Enseñanzas de Régimen Especial: La Difusión del Patrimonio Histórico en los Ciclos Formativos de Talla Artística en Madera y Artes Aplicadas en Escultura
}

La difusión del Patrimonio Histórico es una tarea compleja, multidisciplinar, que requiere de acción, técnicas y recursos materiales y humanos dirigidos a ello. Se trata de una gestión cultural mediadora entre dicho Patrimonio y la Sociedad.

Y es por ello por lo que determinadas enseñanzas especializadas que desde hace años vienen jugando un importante papel de difusión de nuestro Patrimonio deben ser valoradas en relación con esa gestión cultural. Nos estamos refiriendo a las Escuelas de Artes Aplicadas y Oficios Artísticos, consideradas de modo poco objetivo como una suerte de "parientes pobres" del sistema educativo frente a las Escuelas de Bellas Artes, diginificadas después con su ascenso a Facultades, ignorando completamente la gran labor difusora conseguida por estas Escuelas.

En efecto, gran número de profesionales dedicados al mundo artístico en talleres y centros laborales han visto fertilizada su formación práctica de taller con perspectivas netamente teóricas, imprescindibles para mantener el legado cultural que actúa de recordatorio permanente del gran pasado artístico de España. De este modo el contenido multidisciplinar teórico y práctico que se ha estado enseñando en estas Escuelas ha actuado como un mecanismo de valoración y salvaguarda de numerosas técnicas artísticas olvidadas por las Facultades de Bellas Artes, y que forman parte de nuestro Patrimonio Histórico: la Metalistería, la Ebaniste- ría, los Esmaltes, y muchas otras se han salvado del olvido gracias a unos profesionales que se han formado para valorar y conocer la elaboración de objetos de uso cotidiano, tan familiares que llegan a hacerse imprescindibles en la vida diaria.

Esa labor ha ido acompañada de un estudio teórico de carácter diacrónico, incluido dentro del diseño curricular de estos centros. En concreto, la Escuela "León Ortega" de Huelva, donde desarrollamos nuestra labor docente como profesora de Historia del Arte, en los Ciclos Formativos de Artes Aplicadas, y profesor de Volumen, respectivamente, en los mismos Ciclos, es un ejemplo de cómo los contenidos teóricos ayudan a difundir y preservar técnicas artísticas de épocas pasadas, que también forman parte de nuestro Patrimonio Histórico pero que han sido poco valoradas, de esa forma los alumnos profundizan en la Historia de las Artes Aplicadas de Andalucía, conociendo la evolución histórica de las técnicas y los materiales, ayudando a la difusión del Patrimonio considerado como menor.

Asimismo el actual sistema modular permite configurar acertadamente el diseño de estos estudios con una atención más detallada, ya que el alumno se centra en los contenidos de un modo más reflexivo, y al mismo tiempo práctico. Además, el incluir dentro de estos módulos temas como el análisis de la documentación y recopilación de datos históricos y contemporáneos de las técnicas de
Artes Aplicadas, permite a los alumnos convertirse en agentes transmisores de conocimientos, que de modo indirecto contribuyen a preservar una parte de nuestro Patrimonio Histórico, tantas veces olvidado en favor de las grandes manifestaciones artísticas.

Así en el módulo de Talla los alumnos estudian la aparición en la Antigüedad de la talla de madera y piedra, y hacen un recorrido diacrónico a lo largo de la Historia, hasta el siglo $X X$, con especial atención a Andalucía, de manera que los alumnos aprenden las bases de las técnicas que emplean de modo que las difundan. Además, estos Ciclos vinculan al alumno con el mundo profesional, si bien sería de desear una ampliación superior al plazo actual: 2 años, de forma que el alumno pudiera profundizar en mayor grado de lo que ahora puede hacerlo. No obstante, la labor de difusión de dichas técnicas sigue vigente.

\footnotetext{
María Dolores Caballero Rodríguez Profesora de Artes Plásticas y Diseño en la disciplina de Historia del Arte. José Pedro Aznárez López Profesor de Artes Plásticas y Diseño en la disciplina de Volumen.
}

\section{Información:}

Escuela de Artes Plásticas y Diseño León Ortega c/Escultora Miss Whitney, 56 21003 Huelva

Tfno: 959-27-|9-8|. 